\title{
The Relationship between Transitive and Intransitive Verbs in English Language
}

\author{
Teddy Fiktorius \\ SMA Bina Mulia Pontianak, Kalimantan Barat, Indonesia \\ fiktoriusteddy@yahoo.com
}

\begin{tabular}{|c|c|}
\hline Article Info & ABSTRACT \\
\hline $\begin{array}{l}\text { Article History } \\
\text { - Article Received } \\
17^{\text {th }} \text { August } 2019 \\
\text { - Article Reviewed } \\
9^{\text {th }} \text { September } 2019 \\
\text { - Article Accepted } \\
11 \text { October } 2019\end{array}$ & $\begin{array}{l}\text { In the current research, the researcher employs descriptive method (library } \\
\text { research) to elaborate on the relationship and differentiation between the } \\
\text { English language transitive and intransitive verbs. The first parts explore the } \\
\text { theoretical framework of the relationship and differentiation equipped with } \\
\text { various sentences samples. The next part discusses the implications for English } \\
\text { language teachers in coping with some grammatical confusion. Finally, some } \\
\text { solutions as well as recommendations are proposed. }\end{array}$ \\
\hline $\begin{array}{l}\text { Keywords } \\
\text { transitive verbs } \\
\text { intransitive verbs } \\
\text { grammatical confusion }\end{array}$ & \\
\hline
\end{tabular}

\section{INTRODUCTION}

Verbs can be so tricky that even the best grammar students might be often confounded by the difference between transitive and intransitive verbs. The confusion with the use of the transitive and intransitive verbs can be resolved as a grammar point becomes clear with an understanding of objects. When using a dictionary to look up verbs, we may have been puzzled by the abbreviations vi (intransitive verb) and vt (transitive verb).

Kline and Demuth[1], Berry[2], Azar and Hagen[3], Crystal[4], and Francez[5] claim that it is the object of any given sentences that makes the difference, a clear grammatical point that may serve as a clue to determine if the sentences have a transitive verb or intransitive verb. So, what is the confusion all about? Why should the students know the difference between transitive and intransitive verbs? Why is it important to know the difference between transitive and intransitive verbs?

Understanding the different functions of those two verbs can help any students dealing with the use of those two types of verbs avoid grammatical mistakes, such as incomplete sentences that may result into misleading sentences that lose its exact meaning. Students, particularly the speakers of other languages, often have difficulty determining which verbs require an object, and which do not. When students confuse transitive and intransitive verbs, the sentences they construct both orally and in written may be incomplete.

This current paper is written to provide us with better insights into the difference of transitive and intransitive verbs, which in turn help us comprehend and master the basics of English grammar. Best of all, when we understand the underpinnings of our language, learning a language, particularly English language, will be fun as it should be.

\section{LITERATURE REVIEW}

\section{a. Transitive and Intransitive Verbs}

An action verb which has an object, either direct or indirect, is called a transitive verb, while an action verb which does not have an object is called an intransitive verb. The differences between the transitive and intransitive verbs are presented in the following sections. 


\section{Transitive Verbs}

The word "transitive" sounds complex, but in reality identifying transitive verbs is really not that difficult (more details on how to determine which verb is transitive or intransitive are presented in section "Transitive or intransitive: Which is it?"). Transitive verbs express an action and are followed by an object.

The grammatical term object means a noun, pronoun or noun phrase that are impacted by the action of the verb in a given sentence[5]. This circularity causes problems for some people. It is perhaps easier to think of what a direct object is and what it is not. A direct object is a noun phrase that does not function as a subject complement; that is, it does not describe the subject. Compare the following sentences:

Sumanto looks tired.

(Linking, Nominal Subject Complement)

Sukamto sells cars.

(Transitive, Direct Object)

Let us first look at a couple of examples of transitive verbs in sentences as in:

Suminem sent (transitive verb) a letter (direct object) from Canada.

Sukiyem left (intransitive verb) the bag (direct object) on the floor.

Sujoko took (intransitive verb) his son (direct object) to the mall.

In each of the example above, the subject performs an action and there is an object that receives the action. Followed by the verb, the direct object answers the question What? or Whom? [3] [4] [5].

What does Suminem send? A postcard.

What did Sukiyem leave? The keys.

Whom did Sujoko take? His son.

What is wrong with the sentences below? Examples:

Suminem sent from Canada.

Sukiyem left on the floor.

Sujoko took to the mall.

Without the use of a direct object the sentences above make no sense. The meaning of a transitive verb is incomplete without a direct object, as in the following examples:
Suminem sent from Canada. (Incomplete)

Suminem sent a parcel from Canada. (Complete)

Sukiyem left on the floor. (Incomplete)

Sukiyem left the bag on the floor. (Complete)

Sujoko took to the mall. (Incomplete)

Sujoko took his son to the mall. (Complete)

\section{Intransitive Verbs}

An intransitive verb is simply defined as a verb that does not take a direct object. There is no word in the sentence that tells who or what receives the action. While there may be a word or phrase following an intransitive verb, such words and phrases typically answer the question "how". In other words, Azar and Hagen[3], Crystal[4], and Francez[5] note that intransitive verbs can be followed by adverbs.

Most intransitive verbs are complete without a direct object. Here are some examples of intransitive verbs in sentences:

Sujanah grew up.

Sukirman slept soundly.

Sumaimun shouted inside the hall.

In the sentences above, "Sujanah", "Sukirman" and "Sumaimun" are the subjects, and "grew up", "slept", and "shouted" are the intransitive verbs, while "soundly" is an adverb of manner and "inside the hall" is a prepositional phrase of place.

Let us take a look at another couple of examples of intransitive verbs in the following sentences.

It rained.

It snowed.

The sentences above are complete. The subject "it" is followed by the intransitive verb "rained" and "snowed".

Intransitive verbs can be followed by a prepositional phrase or an adverb to add to the thought being expressed, but they can never be followed by a noun, which would act as the object of the sentence.

Examples of intransitive verbs followed by prepositions include:

Sujanah grew up to be a singer.

Sukirman slept on the sofa. 
Sumaimun shouted behind the door.

"On the sofa" and "behind the door" are prepositional phrases, not direct objects. The word "on" and "behind" are prepositions that introduce the prepositional phrase. The same can be said of "to be a singer", which is yet another phrase.

It rained across the region.

It snows in Alaska.

"Across the region" and "in Alaska" are prepositional phrases adding to the sentences' meanings by answering the questions: "where did it rain?" and "where does it snow?".

There are two kinds of intransitive verbs, namely linking verbs and action verbs. The sentences above use action verbs. Linking verbs do not express action. Like their name suggests, they simply link the sentence subject to the predicate. The most common linking verbs are all versions of the verb to be: am, is, are, was, were, has been, will be, etc[3].

Here are several examples of linking verbs that are intransitive verbs, followed by the appropriate descriptors.

The dogs are friendly.

The guests have been late.

Suminah will be 17 in July.

Even though the sentences, "The dogs are friendly", "The guests have been late", and "Suminah will be 17 in July" seem as if they should have a direct object, there really is no receiver of the action. The subjects "the dogs", "the guests", and "Suminah" are followed by the linking intransitive verb "to be", modified by the age 17 and the prepositional phrase "in July" (sentence 3). The results are three complete, grammatically correct sentences as seen in the above table.

\section{b. Transitive or Intransitive: Which Is It?}

"How can we know the difference between transitive and intransitive verbs?" appears to be a very common question asked by whoever dealing with the study of English grammar, particularly the verb. To determine if a verb in a given sentence is transitive or intransitive, we can simply ask "Whom?" or "What?" after the verb. If there is an answer in the sentence, the verb is transitive. If no answer can be found, the verb in the given sentence is intransitive [3] [4] [5].
Particularly, intransitive verbs can stand alone as the whole predicate, although they may also have adverbial modifiers. Examples are the verbs in:

The fish swam.

The fish swam gracefully.

The fish swam in the tank.

We can perform the following tests to determine if a verb is intransitive:

1. Divide the predicate into phrases and see if it contains only a VP (verbal phrase) or a VP + an adverbial phrase.

2. If we are not sure if the phrase modifying the VP is adverbial, try replacing it with a prototypical adverb like there or then. If this works, the phrase is functioning adverbially.

Some verbs may be transitive in one sentence and intransitive in another, but there are some verbs which are always one or the other. A good dictionary will tell us if a verb can be either or if it is always one or the other (the the usual abbreviation is v.i. for intransitive verb and v.t. for transitive verb).

\begin{tabular}{|c|c|c|}
\hline Sentences & $\begin{array}{l}\text { "What?" or } \\
\text { "whom?" }\end{array}$ & $\begin{array}{l}\text { Type of } \\
\text { verb }\end{array}$ \\
\hline $\begin{array}{l}\text { Sumaimum eats } \\
\text { cake. }\end{array}$ & $\begin{array}{l}\text { cake } \\
\text { (what) }\end{array}$ & Transitive \\
\hline $\begin{array}{l}\text { She phoned her } \\
\text { mom. }\end{array}$ & $\begin{array}{l}\text { her mom } \\
\text { (whom) }\end{array}$ & Transitive \\
\hline $\begin{array}{l}\text { We waited for the } \\
\text { taxi. }\end{array}$ & no answer & Intransitive \\
\hline $\begin{array}{l}\text { They slept for a } \\
\text { while. }\end{array}$ & no answer & Intransitive \\
\hline $\begin{array}{l}\text { I } \underline{\text { drew }} \text { that } \\
\text { picture. }\end{array}$ & $\begin{array}{l}\text { that picture } \\
\text { (what) }\end{array}$ & Transitive \\
\hline $\begin{array}{l}\text { They drew so } \\
\text { slowly. }\end{array}$ & no answer & Intransitive \\
\hline
\end{tabular}

As seen in the table above, the transitive and intransitive verbs refer to "action verbs". We can, therefore, easily provide the answer to the question of "what?" or "whom". Additionally, we can also answer "What" questions after "to be" and "to become".

However, these verbs are always intransitive. They are linking, not action verbs. Linking verbs are never transitive. Crystal [4] explains that linking verb is also called copulative verb or copular verb. It is a main verb in any given sentences which, like the verb "be", links 
a subject to a subject complement. "be" is by far the most common copular verb and is called the copula:

Those children are playful.

The situation is stressful.

I am strong.

The seminar was a great success.

The cookies were delicious.

The ideas have been reasonable.

Other copular verbs add an extra meaning to the neutral meaning of "be", as shown in the sentences as follows:

Those children look playful.

The situation remains stressful.

\section{I grow strong.}

The seminar proved a great success.

The cookies smelt delicious.

The ideas sounded reasonable.

Some other verbs that can act as copular verbs copular verb include: feel, taste, appear, seem, become, get, go, turn.

Note that "be" and some other copular verbs can also be followed by an adverbial, as can be seen in the following sentences:

Those children are playful at school.

The situation remains stressful in the conflict.

\section{I grow strong unexpectedly.}

The seminar proved a great success in 2019.

The cookies smelt delicious on the plate.

The ideas sounded reasonable in the meeting.

Some transitive verbs can have their objects left out of the sentence when the meaning is clear from the context. Let us take a close look at the following sentences:

The man has smoked (...) since he was 20 . (understood: cigarettes)

The guitarist plays (...) beautifully. (understood: the guitar)

The chidren were drinking (...) so quickly. (understood: the juice)
The rock star was singing (...) on the stage. (understood: the song)

The daughter phoned (...) silently. (understood: her father)

The chef has cooked (...) for years. (understood: spaghetti)

Other verbs of which objects can be omitted from the sentence when the meaning is clearly understood from the context include: answer, ask, dance, eat, fail, read, wash, win, write.

\section{c. Either Transitive or Intransitive}

Depending on the context in the sentence, many verbs in English language can be used as either transitive or intransitive [4] [5]. In the following pairs of sentences, the first sentence uses the verb transitively and the second uses the same verb intransitively.

\section{Sentence sample 1}

According to the doctor, the patients must stop their smoking habit as soon as possible. (transitive)

In this example, it is clearly seen that the verb "stop" takes a direct object, which is the noun phrase "their smoking habit" located directly after the verb "stop".

The children would like to play the games longer, but they must stop before their mom arrives. (intransitive)

In this example, the verb "stop" does not take a direct object. Therefore, the verb in the given sentence is intransitive.

\section{Sentence sample 2}

The well-known writer has translated some of his books from Czech into English very smoothly. (transitive)

In this example, the verb "translate" is used transitively and takes the noun phrase "some of his books" as a direct object.

Let's hope all the hard work will translate into profits. (intransitive)

In this example, the verb "translate" is used intransitively and takes no direct object. 


\section{Sentence sample 3}

The loyal supporters attentively watched the final football match of their favourite team. (transitive)

In this example, the verb "watch" is used transitively and takes the noun phrase "the final football match of their favourite team" as a direct object.

The teacher watched while the naughty students reluctantly picked up the unused plastic bags. (intransitive)

In this example, the verb "watched" is used intransitively. Therefore, the verb takes no direct object.

\section{Sentence sample 4}

The landlord has arrogantly forced the dwellers to move all the boxes behind the room. (transitive)

In this sentence, "move" is used as a transitive verb and takes the noun phrase "all the boxes behind the room" as a direct object.

The pedestrians moved across the street quickly in an attempt to avoid the car crash. (intransitive)

In the sentence above, the verb "moved" is used as an intransitive verb and takes no direct object.

Other verbs that can be used as either transitive or intransitive include: soak, socialise, pull, meet, see, claim, clap, saw, shout, shoot, plan, etc.

\section{METHODOLOGY}

The researcher uses descriptive method or library research to the current research problems. This research is conducted by expressing some useful information from the available documents in the field of the English language transitive and intransitive verbs.

The main aim of the present research is to provide come current information in the field of the relationship and differentiation between the English language transitive and intransitive verbs that will lead to promoting some applicable implications for English language teachers in coping with some grammatical confusion.

\section{RESULT AND DISCUSSION}

English sentences may be incomplete if transitive and intransitive verbs are confused by the users both in written and oral forms, which in turn may result into unclear communications. Nonnative English speaking students, especially those coming from Asian countries, frequently confuse the use of transitive and intransitive verbs [4].

The following sentences are presented to show how the transitive verb "lay" and the intransitive verb "lie" are used in a wrong way. Compare the following sentences:

a) The child wanted to lay down on the mattress.

b) The child wanted to lie down on the mattress.

c) The child wanted to lay his body on the mattress.

d) The child wanted to lie his body on the mattress.

"Lay" requires an object as it is a transitive verb, which means "to put somebody or something carefully in a particular position or on a surface", as in:

e) Please remember to lay the bag on the table. (to lay $=$ to infinitve; the bag $=$ a noun phrase).

f) He laid (the past form of "lay") the child gently down on her bed. (laid = past form; the child $=\mathrm{a}$ noun phrase)

g) They have laid the dead body on the floor. (laid = past participle; the dead body $=$ a noun phrase)

h) The man is laying new electricity cables in our street. (laying $=$ present participle; new electricity cables $=$ a noun phrase)

On the other hand, "lie", which means to be in or move into a flat or horizontal position, is an intransitive verb and cannot take an object after it. However, "lay" is frequently used as an intransitive verb as illustrated in sentences a), b), c), and d) above. Part of the confusion seems to be related to the fact that "lay" is the past form of "lie", whereas "laid" is the past form of "lay".

When talking about the relationship between transitive and intransitive verbs in the EFL classroom setting, providing the students with some explanation that some verbs are transitive and some are intransitive does not really help them much. Such explanation may only serve as basic knowledge in an important first step. Yet, it appears to be commonplace that most of EFL teachers frequently perform such a teaching procedure when trying to cope with the students' confusion with the differences between transitive and intransitive verbs. 
Azar and Hagen[3] claim that the number of intransitive verbs in English is relatively small. An effective approach an EFL teacher may apply consists of at least three steps as explained below.

First, develop a list of the most commonly used intransitive verbs and distribute it to the students so that they can study independently. Self-learning is seen as one of the best way to promote better memorisation drill. By having the list, the students are given a broader chance to memorise the listed intransitive verbs through repetitions that the students can do anytime and anywhere as they wish.

Then, explain to the students that most verbs that are not on the list will be transitive verbs and will require a noun phrase object. Listing the intransitive verbs only (as shown in step one above), which are not as many as the transitive verbs, seems to be a good idea that the teacher is not burdened to list down the transitive verbs that outnumber the intransitive verbs.

Finally, the possible last step of maximalising the use of the list of the intransitive verbs is to have the students refer to the list during the editing phase of all writing activities.

Briefly, by having the students get involved in the learning experience as discussed above, it is expected that the students will subsequently demonstrate speedy improvement on the mastery of the use of both transitive and intransitive verbs.

\section{CONCLUSION}

The general sentence pattern of "subject + verb + object" is a foundation in the English language. It is one of the most frequently used, as well as one of the most basic. Students learn this sentence structure quite early in their growth and development. Nevertheless, speakers of other languages often have difficulty determining which verbs take an object, and which do not. A very simple rule we can use to tell if a verb we are looking at is transitive or not is simply to ask ourselves if the thing the verb is being done to is visible within the sentence. If it is, the sentence probably has a transitive verb.

The main reason why we should know the difference between transitive and intransitive verbs is that understanding the different functions of these two verbs can help students avoid mistakes, such as incomplete sentences. When the students confuse transitive and intransitive verbs, their sentences may be incomplete. The result is confused communications in which the exact meaning is missing. In the EFL classroom setting, explaining to the students that some verbs are transitive and some are intransitive should be in an important initial step.

\section{REFERENCES}

[1] Kline, M. \& Demuth, K. 2013. "Syntactic Generalization with Novel Intransitive Verbs". Journal of Child Language, 1-32.

[2] Berry, R. 2015. From Words to Grammar: Discovering English Usage. New York: Routledge.

[3] Azar, B. S. \& Hagen, S. A. 2017. Understanding and Using English Grammar. London: Pearson Education.

[4] Crystal, D. 2017. Making Sense: The Glamorous Story of English Grammar. Oxford: Oxford University Press.

[5] Francez, N. 2017. "A Proof-Theoretic Semantics for Transitive Verbs with an Implicit Object". Association for Computational Linguistics, 59-67. 